\title{
Above-Ground Biomass Estimation of Successional and Mature Forests Using TM Images in the Amazon Basin
}

\author{
Dengsheng $\mathrm{Lu}^{1}$, Paul Mausel ${ }^{2}$, Eduardo Brondizio ${ }^{3}$ and Emilio Moran ${ }^{3}$ \\ Center for the Study of Institutions, Population, and Environmental Change \\ (CIPEC), Indiana University, Bloomington, Indiana 47408, USA, ph. 812-856- \\ 5767, fax 812-855-2634, e-mail: dlu@indiana.edu ${ }^{1}$ \\ Department of Geography, Geology, and Anthropology, Indiana State University, \\ Terre Haute, Indiana 47809, USA, ph. 812-237-2254, fax 812-237-8029, \\ gemause@scifac.indstate.edu ${ }^{2}$ \\ Anthropological Center for Training and Research on Global Environmental \\ Change, Indiana University, Bloomington, Indiana 47405, USA, ph. 812-855- \\ 6182, fax 812-855-3000, ebrondiz@indiana.edu and moran@indiana.edu ${ }^{3}$
}

\begin{abstract}
Above-ground biomass estimation of successional and mature forests in moist tropical regions is attracting increasing attention. Because of complex stand structure and abundant vegetation species, rarely has remote-sensing research been successfully conducted in biomass estimation for moist tropical areas. In this paper, two study areas in the Brazilian Amazon basin-Altamira and Bragantina - with different biophysical characteristics were selected. Atmospherically corrected Thematic Mapper (TM) images and field vegetation inventory data were used in the analysis, and different vegetation indices and texture measures were explored. Multiple regression models were developed through integration of image data (including TM bands, different vegetation indices, and texture measures) and vegetation inventory data. These models were used for biomass estimation in both selected study areas. This study concludes that neither TM spectral bands nor vegetation indices alone are sufficient to establish an effective model for biomass estimation, but multiple regression models that consist of spectral and textural signatures improve biomass estimation performance. The models developed are especially suitable for above-ground biomass estimation of dense vegetation areas.

Keywords: biomass estimation, successional and mature forests, Amazon basin, Thematic Mapper, vegetation index
\end{abstract}




\section{Introduction}

Biomass estimation for tropical forests has received much attention in recent years because the change of biomass regionally is associated with important components of climate change. Biomass determines potential carbon emission that could be released to the atmosphere due to deforestation or conversion to non-forest land use. Therefore, accurate biomass estimation is necessary for better understanding deforestation impacts on global warming and environmental degradation.

Computer-processed remotely sensed data are possibly the best data for economical biomass estimation in the tropical region over large areas. Although various methods for biomass estimation have been tested (Gillespie et al. 1992, Overman et al. 1994, Roy and Ravan 1996), rarely has research successfully been conducted in a large area in moist tropical regions due to the complex tropical forest stand structure and abundant tree species. Previous research mainly used spectral signatures to establish biomass estimation models (Nelson et al. 1988, Franklin and Hiernaux 1991, Leblon et al. 1993, Nelson et al. 2000, Steininger 2000), but ignored spatial information largely due to a lack of understanding about the relationships between biomass and spatial signatures. However, spatial information could be an important factor in improving biomass estimation accuracy even though many uncertainties exist. For example, what types of texture measures are appropriate to extract biomass information? What size of moving window for selected texture measures can most effectively extract biomass information? Which models can be used to estimate biomass using remote-sensing technology? How do different biophysical environments influence biomass estimation? In order to explore biomass estimation using remote-sensing data, two study areas, each having different vegetation growth rates, soil conditions, and land-use history, are selected. Different types of vegetation indices and texture measures are tested. This paper develops biomass estimation models for successional and mature forest biomass estimation in the Amazon basin.

\section{Study Areas}

The Altamira study area is located along the Transamazon Highway in the Brazilian state of Para (Fig. 1). The city of Altamira and the Xingu River anchor the eastern edge of the study area. In the 1950s an effort was made to attract colonists from all over Brazil, who came and settled along streams as far as $20 \mathrm{~km}$ from the city centre. With the construction of the Transamazon Highway in 1970, this population and older caboclo settlers from earlier rubber eras claimed land along the new highway and legalised their land claims. Geopolitical goals and political economic policies that transferred production of staples like rice, corn, and beans from the most southern Brazilian states to more northern regions drove Early settlement. The region has had a gradual shift to a more diverse set of land uses: pasture, cocoa, sugar cane, black pepper, and staple crops. Mahogany is beginning to be planted in cocoa groves as a diversification strategy and can be 
expected to benefit landowners who have the best soils in the area (Moran et al. in press). The dominant native types of vegetation are mature moist forest and liana forests. Nutrient-rich alfisols, as well as nutrient-poor ultisols and oxisols were found in the Altamira study area. Altamira has experienced high rates of deforestation and secondary succession associated with implementation of agropastoral projects. Annual rainfall in Altamira is approximately $2,000 \mathrm{~mm}$ and is concentrated from late October through early June. Average temperature is about $26^{\circ} \mathrm{C}$.

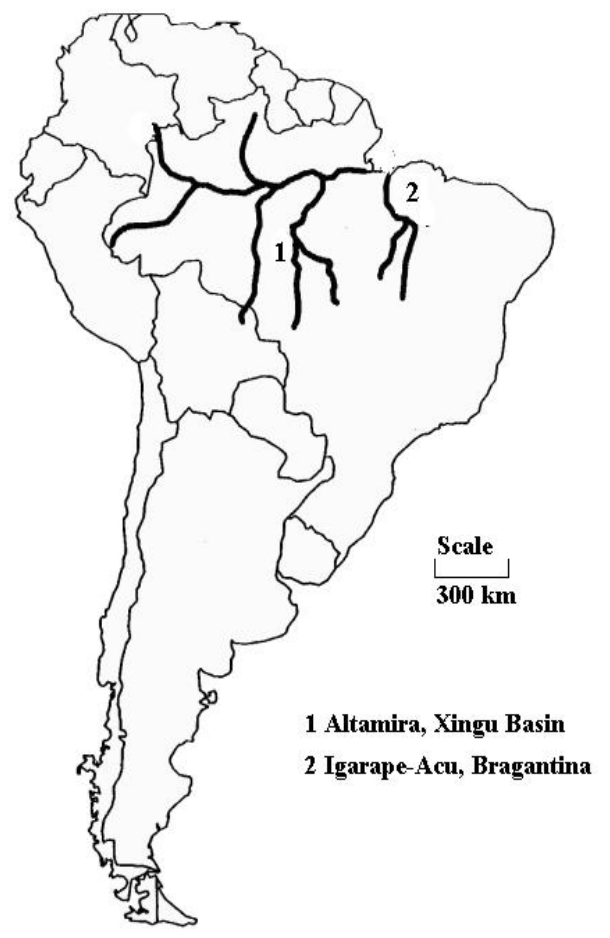

Fig. 1. Location of selected study areas

The Bragantina study area selected is located within the municipality of Igarapé-Açú in the state of Pará. The vegetation in this region is mostly composed of secondary-growth forest (capoeira), flooded forest (igapo), and a few remaining areas of dense forest. At the beginning of the twentieth century, almost one million hectares of dense tropical rain forest covered the Bragantina region; however, less than 2 percent of the forests remained by 1960. The dense forest that once surrounded the town of Castanhal had an average height of 23 meters. Heavy occupation of this region has eliminated almost all dense forests and transformed 
the landscape into a mosaic comprised of a variety of secondary vegetation (Tucker et al. 1998). Currently, secondary succession in all stages of regrowth dominates the landscape. The main agricultural products are passion fruit (maracuja), manioc, oil palm, rice, corn, beans, and cotton. Other important crops are pepper, papaya, tobacco, melon, sugar cane and beet, rubber, avocado, citrus, coconut, banana, cocoa, guarana, mango, and caju (Ibid.). Nutrient-poor oxisols and ultisols dominate in this area. Land use in the Bragantina region has gone through several phases, and today the dominant form is short-fallow swidden cultivation and pasture development. Cultivation of secondary-growth areas has been common for decades, and islands of mature forest are rare (Moran et al. in press). The long settlement history, high human population density, repeated land clearing (including burning) over the past century in Bragantina has degraded the landscape, leading to slower regrowth rates. In Bragantina, annual rainfall ranges from 2,200 to $2,800 \mathrm{~mm}$ with variation as much as $+/-1,000 \mathrm{~mm}$ from the mean. The average annual temperature of this region is $25-26^{\circ} \mathrm{C}$, and the dry period extends from September through November. The region is characterised by high rates of precipitation and a short dry period of at least one month with less than 66 $\mathrm{mm}$ of rainfall.

\section{Methods}

\subsection{Data Collection and Analysis}

A nested sampling strategy, organised by region, site, plot, and subplot, was employed to collect field data. Landsat TM images and GPS devices were used during fieldwork. The region was the categorical level representing the study area that included all sample sites. The site in this region was selected for plot sampling. In general, ten plots $(10 \mathrm{~m} \times 15 \mathrm{~m})$ in each site were allocated in a stratified random fashion, and one randomly selected subplot $(5 \mathrm{~m} \times 2 \mathrm{~m})$ was nested within each plot. Plots were designed to inventory trees, and subplots were used to inventory saplings, seedlings, and herbaceous species. In each plot, all individual trees with a diameter at breast height $(\mathrm{DBH})$ greater than $10 \mathrm{~cm}$ were identified and measured for $\mathrm{DBH}$, stem height (the height of the first major branch), and total height. In the subplot, all saplings (DBH between $2 \mathrm{~cm}$ and 10 $\mathrm{cm}$ ), seedlings (DBH less than $2 \mathrm{~cm}$ ), and herbaceous vegetation (percent of ground cover) were identified and counted. The diameter and total height were recorded for all individuals with DBH between $2 \mathrm{~cm}$ and $10 \mathrm{~cm}$. At each site, soil samples were collected at $20-\mathrm{cm}$ intervals to a depth of $1 \mathrm{~m}$, resulting in five sets of measurements for each sample site. Soil samples were analysed at the soil laboratories in Belem, Brazil, for both chemical and physical properties.

Two models were selected for individual vegetation biomass estimation. Eq. 1 (Nelson et al. 1999) was used to calculate biomass for those trees and saplings with DBHs of less than $25 \mathrm{~cm}$, and Eq. 2 (Overman et al. 1994) was used to 
calculate biomass for those trees with DBHs greater than or equal to $25 \mathrm{~cm}$. Eq. 3 was used to calculate above-ground biomass (AGB).

$$
\begin{gathered}
\ln (\mathrm{DW} 1)=-2.5202+2.14 \ln (\mathrm{D})+0.4644 * \ln (\mathrm{H}) \\
\ln (\mathrm{DW} 2)=-3.843+1.035 \ln \left(\mathrm{D}^{2} \mathrm{H}\right) \\
\mathrm{AGB}=\left(\sum_{i=1}^{m} D W 1_{i}+\sum_{j=1}^{n} D W 2_{j}\right) / \mathrm{AP}+\left(\sum_{k=1}^{s} D W 1_{k}\right) / \mathrm{AS}
\end{gathered}
$$

In these equations, $\ln$ is the natural logarithm, $\mathrm{D}$ is diameter at breast height $(\mathrm{cm}), \mathrm{H}$ is total height $(\mathrm{m}), \mathrm{DW} 1$ is individual tree or sapling biomass $(\mathrm{kg})$ when DBH is less than $25 \mathrm{~cm}$, DW2 is the individual tree biomass when DBH is greater than or equal to $25 \mathrm{~cm}, \mathrm{~m}$ is the total tree number in a plot when DBH is between 10 and $25 \mathrm{~cm}, \mathrm{n}$ is the total tree number in a plot when DBH is greater than or equal to $25 \mathrm{~cm}$, and $\mathrm{s}$ is the total sapling number in a subplot area when DBH is between 2 and $10 \mathrm{~cm}$. AP and AS are the plot area and subplot area $\left(\mathrm{m}^{2}\right)$, respectively, and AGB is the above-ground biomass $\left(\mathrm{kg} / \mathrm{m}^{2}\right)$.

\subsection{Landsat TM Image Processing}

Landsat TM images were obtained for Altamira (image date July 20, 1991 and Bragantina (image date June 21, 1994). The TM images were geometrically rectified and then atmospherically corrected using an improved image-based DOS (dark object subtraction) model ( $\mathrm{Lu}$ et al. in press). Four types of vegetation indices were grouped and used (Table 1):

1. Simple ratio, such as TM 4/3, TM 5/3, TM 5/7, and TM 5/4

2. Normalization ratio, such as NDVI (Normalized Difference Vegetation Index), ND32, ND54, ND53 and ND57

3. Linear combination of multiple bands, such as Albedo, MID57, VIS123, PCA (Principal Component Analysis), and KT (Tasseled Cap) transform

4. Complicated vegetation index, such as ARVI (Atmospherically Resistant Vegetation Index), ASVI (Atmospheric and Soil Vegetation Index), GEMI (Global Environmental Monitoring Index), MSAVI (Modified Soil Adjusted Vegetation Index), and SAVI (Soil Adjusted Vegetation Index)

In addition to the TM bands and different vegetation indices, four types of texture measures - mean Euclidean distance (MED), variance, skewness, and kurtosis (Table 2) -were also tested. Different texture measures combined with different window sizes $(3 \times 3,5 \times 5,7 \times 7,9 \times 9$, and $15 \times 15)$ for each Landsat TM band were tested in Altamira and Bragantina. 
Table 1. Vegetation indices used in research

\begin{tabular}{|c|c|}
\hline Index & Formula \\
\hline ARVI & $(\mathrm{NIR}$ - 2 RED + BLUE)/(NIR + 2 RED - BLUE) \\
\hline ASVI & $N I R+0.5-0.5 \sqrt{(2 N I R+1)^{2}-8(N I R-2 R E D+B L U E)}$ \\
\hline GEMI & $\xi(1-0.25 \xi)-\frac{R E D-0.125}{1-R E D}$ \\
\hline & Where $\xi=\frac{2\left(N I R^{2}-R E D^{2}\right)+1.5 N I R+0.5 R E D}{N I R+R E D+0.5}$ \\
\hline MSAVI & $N I R+0.5-0.5 \sqrt{(2 N I R+1)^{2}-8(N I R-2 R E D)}$ \\
\hline SAVI & $\frac{N I R-R E D}{N I R+R E D+L}(1+L)$ \\
\hline ND53 & (TM 5-TM 3)/(TM 5+TM 3) \\
\hline ND54 & (TM 5-TM 4)/(TM 5+TM 4) \\
\hline ND57 & (TM 5-TM 7)/(TM 5+TM 7) \\
\hline NDVI & (TM 4-TM 3)/(TM 4+TM 3) \\
\hline ND32 & (TM 3-TM 2)/(TM 3+TM 2) \\
\hline KT1 & $\begin{array}{l}0.304 \mathrm{TM} 1+0.279 \mathrm{TM} 2+0.474 \mathrm{TM} 3+0.559 \mathrm{TM} 4+0.508 \mathrm{TM} 5 \\
+0.186 \mathrm{TM} 7\end{array}$ \\
\hline KT2 & $\begin{array}{l}-0.285 \mathrm{TM} 1-0.244 \mathrm{TM} 2-0.544 \mathrm{TM} 3+0.704 \mathrm{TM} 4+0.084 \mathrm{TM} 5 \\
-0.18 \mathrm{TM} 7\end{array}$ \\
\hline KT3 & $\begin{array}{l}0.151 \mathrm{TM} 1+0.197 \mathrm{TM} 2+0.328 \mathrm{TM} 3+0.341 \mathrm{TM} 4-0.711 \mathrm{TM} 5 \\
-0.457 \mathrm{TM} 7\end{array}$ \\
\hline $\mathrm{PC} 1, \mathrm{PC} 2, \mathrm{PC} 3$ & $\begin{array}{l}\text { The constants are similar to the } \mathrm{KT} \text {, but they are dependent on the } \\
\text { given image of the study area. }\end{array}$ \\
\hline VIS123 & TM $1+$ TM $2+$ TM 3 \\
\hline MID57 & TM $5+$ TM 7 \\
\hline Albedo & $\mathrm{TM} 1+\mathrm{TM} 2+\mathrm{TM} 3+\mathrm{TM} 4+\mathrm{TM} 5+\mathrm{TM} 7$ \\
\hline TM 4/3 & TM 4/TM 3 \\
\hline TM 5/3 & TM 5/TM 3 \\
\hline TM 5/4 & TM 5/TM 4 \\
\hline TM 5/7 & TM 5/TM 7 \\
\hline
\end{tabular}


Table 2. Texture measures used in research

\begin{tabular}{|c|c|c|}
\hline Texture & Formula & Notes \\
\hline $\begin{array}{l}\text { Mean Euclidean } \\
\text { Distance (MED) } \\
\left(1^{\text {st }} \text { Order }\right)\end{array}$ & $\frac{\sum\left(X_{i j}-M\right)^{2}}{n-1}$ & $\begin{array}{l}X_{i j \lambda} \text { is reflectance for spectral } \\
\text { band } \lambda \text { and pixel (i, j) of a } \\
\text { multispectral image. }\end{array}$ \\
\hline $\begin{array}{l}\text { Variance (VAR) } \\
\left(2^{\text {nd }} \text { Order }\right)\end{array}$ & $\frac{\left|\sum\left(X_{i j}-M\right)^{3}\right|}{(n-1) V^{\frac{3}{2}}}$ & $\begin{array}{l}X_{c \lambda} \text { is reflectance for spectral } \\
\text { band } \lambda \text { of a window's centre } \\
\text { pixel. }\end{array}$ \\
\hline $\begin{array}{l}\text { Skewness (SK) } \\
\left(3^{\text {rd }} \text { Order }\right)\end{array}$ & $\frac{\sum\left(X_{i j}-M\right)^{3}}{(n-1) V^{\frac{3}{2}}}$ & $\begin{array}{l}X_{i j} \text { is reflectance of pixel } \\
(\mathrm{i}, \mathrm{j}) \text {. } \\
\mathrm{M} \text { is the mean of the moving }\end{array}$ \\
\hline $\begin{array}{l}\text { Kurtosis }(\mathrm{KU}) \\
\left(4^{\text {th }} \text { Order }\right)\end{array}$ & $\frac{\sum\left(X_{i j}-M\right)^{4}}{(n-1) V^{2}}$ & $\begin{array}{l}\text { where } M=\frac{\sum X_{i j}}{n} \\
\mathrm{~V} \text { is variance. } \\
\mathrm{N} \text { is number of pixels in a } \\
\text { window. }\end{array}$ \\
\hline
\end{tabular}

\subsection{Integration of Biomass and Remotely Sensed Data}

Remotely sensed data are comprehensive responses of vegetation stand structure, vegetation density, and vegetation species composition. Different forest stand structures have different reflectance and texture patterns in various wavelengths, and the relationships between biomass and remotely sensed data are different. Pearson's correlation coefficient is used to analyse such relationships. It measures the strength of linear relationships between two variables. If the coefficient is close to 1 , it means there is a strong relationship between them. In this research, one variable is biomass; another variable is the remotely sensed data, such as single TM band, vegetation index, and texture measure. Using biomass as a dependent variable and remote-sensing data such as TM band, vegetation indices, and texture measures as independent variables, multiple regression models are used to establish the relationships between biomass and remote-sensing data. The critical step is to find the appropriate independent variables so the combination of multiple independent variables can provide the best-estimated results. The coefficient of determination $\left(\mathrm{R}^{2}\right)$ is an indicator that can be used to determine whether or not the regression model is good, because $\mathrm{R}^{2}$ measures the percent of variation explained by the regression model. Stepwise regression analysis was used to find the best independent variable combination. 


\section{Results}

Linear regression models were developed using the method described. Table 3 provides a comparison of the best regression models identified, based on a single TM band, a single vegetation index, a single texture measure, and a combination of different image bands. It indicates that TM 5 is the best single band that has the highest regression coefficient in Altamira, but band TM 4 is best in Bragantina. Vegetation indices slightly improve relationships between biomass and spectral signatures in Altamira, and texture measures significantly improved the regression coefficients in Altamira, but they did not improve the regression coefficients in Bragantina. In Altamira, variance with TM 2 with a 9x9 window size is the best texture measure combination, and in Bragantina it is variance with TM 5 with a $15 \times 15$ window size. Table 3 also implies that single TM band, single vegetation index, or single texture measure did not have sufficiently high regression coefficients to develop biomass estimation models. Therefore, it may be necessary to seek two or more independent variables in order to improve the relationships between biomass and remotely sensed data.

Table 3. Comparison of regression coefficients among different models

\begin{tabular}{|c|c|c|c|c|c|}
\hline \multirow{2}{*}{$\begin{array}{l}\text { Independent } \\
\text { Variables }\end{array}$} & & \multicolumn{2}{|c|}{ Altamira } & \multicolumn{2}{|c|}{ Bragantina } \\
\hline & & $\begin{array}{c}\text { Independent } \\
\text { Variable }\end{array}$ & $\mathrm{R}$ & $\begin{array}{c}\text { Independent } \\
\text { Variable }\end{array}$ & $\mathrm{R}$ \\
\hline Best single & TM & TM 5 & 0.627 & TM 4 & 0.837 \\
\hline image band & VI & ND54 & 0.635 & KT1 & 0.835 \\
\hline & Txt & VARtm2 9 & 0.841 & VARtm5 15 & 0.551 \\
\hline Best & $\mathrm{TM}$ & TM $5+$ & 0.874 & TM 4+ & 0.883 \\
\hline combination & $\begin{array}{l}+ \text { Txt } \\
\text { VI }+ \\
\text { Txt }\end{array}$ & $\begin{array}{c}\text { VARtm2_7 } \\
\text { KT1+ } \\
\text { VARtm2_9 }\end{array}$ & 0.878 & $\begin{array}{l}\text { SKtm4_9 } \\
\text { PC2+ } \\
\text { VARtm5 } 15\end{array}$ & 0.851 \\
\hline
\end{tabular}

Note: VI is vegetation index; Txt is texture measure.

Stepwise regression analysis indicates that, in the multiple regression models, if the independent variables consist of two or more TM bands, two or more vegetation indices, combinations of TM bands with vegetation indices, and two or more texture measures, the regression coefficients are not significantly improved. Only the combination of TM bands with texture measures or vegetation indices with texture measures can significantly improve the $\mathrm{R}$ values. This is because high correlation exists between spectral signatures or between textural signatures, or very weak relationships exist between biomass and selected image bands. However, the information associated with spectral and textural signatures is complementary. For example, in Altamira the TM reflectance or vegetation indices are not strongly related to biomass, but some specific texture measures such as VARtm2_9 (VARIANCE combined with TM 2 and 9x9 window size) are strongly related to biomass. In Bragantina, spectral signatures such as TM 4 have strong correlations with biomass, but no texture measures have strong correlations 
with biomass. The results (Table 3) show that integration of spectral and textural signatures improved relationships with biomass.

Table 4 summarises the best regression models that were used for biomass estimation in the Altamira and Bragantina study areas. Visually comparing the biomass estimated image with TM 4-5-3 colour composite indicates that high biomass amount corresponds to higher vegetation growth stages. For example, those areas where biomass is greater than $20 \mathrm{~kg} / \mathrm{m}^{2}$ are dominated by mature forest, while successional forest biomass falls in the range between 0 to $20 \mathrm{~kg} / \mathrm{m}^{2}$.

Table 4. Models used for biomass estimation in selected study areas

\begin{tabular}{llll}
\hline Study Area & Regression Models & $\mathrm{R}$ & Beta value \\
\hline Altamira & $122.288-1.078 * \mathrm{KT} 1$ & 0.878 & $-0.28(\mathrm{sp}),-0.72(\mathrm{txt})$ \\
Bragantina & $\begin{array}{l}64.037-1.651 * \text { TM4 } \\
+1.405 * \text { SKtm4_9 }\end{array}$ & 0.883 & $-0.76(\mathrm{sp}), 0.29(\mathrm{txt})$ \\
& & &
\end{tabular}

Note: sp means spectral variables, such as KT1 and TM 4, used in the models; txt means texture variables used in the models.

The Beta value in Table 4 provides a means of measuring the relative changes in variables on a standard scale. It indicates how much change in the dependent variable is produced by a standardised change in one of the independent variables when the others are controlled. The Beta values confirm that texture measure is more important in a study area like Altamira with good soil conditions and fast vegetation growth rates than in a study area like Bragantina with very poor nutrient soil and very slow vegetation growth rate. Texture measure roles in biomass estimation are valuable since they offer an effective method for improving model performance based on the image itself.

\section{Discussion}

When the sites with very young vegetation ages (two one-year-old sites in Altamira and two two- and three-year old sites in Bragantina) were excluded, the regression coefficients and estimation errors were significantly reduced. This means the younger initial secondary succession (SS1) sites are the main cause of estimation bias. There are at least two reasons for this. First, saplings and seedlings dominate SS1 vegetation, which lacks obvious stratification of stand structure (texture measures cannot effectively extract biomass texture information from SS1 vegetation reflectance). Second, SS1 vegetation is not sufficiently dense to cover the ground, and the information captured by sensor is a mixture of soil and vegetation. The soil colour, soil moisture, and soil mineral composition can significantly influence the reflectance of these SS1 sites. This leads to wide reflectance ranges of SS1 vegetation, which result in low correlation between SS1 vegetation reflectance and SS1 biomass. Although some vegetation indices such as SAVI and MSAVI can reduce the influence of soil conditions, they are weakly 
related to biomass because they use near infrared (TM 4) and red (TM 3) bands that are weakly correlated with biomass.

Different soil conditions, precipitation patterns, and land-use history induce different vegetation stand structures, canopy shadows, and species compositions, resulting in different relationships between biomass and remotely sensed data $(\mathrm{Lu}$ 2001). In a study area with fast vegetation growth rate such as Altamira, complex stand structure and canopy shadows compromised the correlation between biomass and TM spectral signatures but enhanced relationships between biomass and texture information. In contrast, in a study area with slow vegetation growth rates, such as Bragantina, spectral signatures are more strongly related to biomass than are texture data. Thus, in the multiple regression models for biomass estimation, incorporation of texture data in the models in the Altamira study area is more important than in the Bragantina study area for improving the estimation accuracy.

A variety of vegetation indices and texture measures have been developed. A logical question to ask however, is 'which vegetation index and which texture measure can be used to establish biomass estimation models using remotely sensed data'? Previous literature has not discussed these problems to any great extent. Many applications of texture analyses to remotely sensed data are focused on improving classification accuracy by discriminating forest-cover types from non-forest land-cover types (Gordon and Phillipson 1986, Franklin and Peddle 1989, Peddle and Franklin 1991, Jakubauskas and Price 1997). Rarely has research focused on improving biomass estimation, especially for tropical successional and mature forests. Research attempting to find which texture measure-what window sizes using which wavelengths - performs better in improving biomass estimation accuracy is uncommon. Although many texture measures have been developed (Haralick et al. 1973, Haralick 1979, Marceau et al. 1990), there has been little research on how to effectively extract biomass texture information. This research indicates that texture information is a very important factor in improving model estimation performance, especially in a study area with fast vegetation growth rates and complex stand structure. The importance of texture information in a model varies. It is a difficult task to find an appropriate texture measure that is strongly related to biomass because only some texture measures with a specific window size and image band can effectively extract biomass texture information. Results can differ in different study areas. Purely textural information is not sufficient to establish a model for estimating biomass with high accuracy. More detailed research on extraction of biomass texture information is necessary in the future.

Vegetation indices can partially reduce the impacts on reflectance caused by environmental conditions and shadows. Different vegetation indices have been developed and used for classification or biomass estimation (Anderson and Hanson 1992, Anderson et al. 1993, Eastwood et al. 1997). Bannari et al. (1995) reviewed more than forty indices presented through the literature. However, not all vegetation indices are significantly correlated with biomass. In a selected study area, it is not easy to effectively and quickly determine one or more vegetation indices that are appropriate for use in the model development. Lu (2001) analysed 
and compared twenty-three vegetation indices and identified that linear TM band combinations (e.g., the first components of PCA or Tasseled Cap transform) have stable and good relationships with biomass. The previous analysis indicated that vegetation indices alone are not sufficient to establish an effective model for biomass estimation. This is especially true in a study area with fast vegetation growth rates and complex stand structure, largely because complex stand structure and canopy shadow negatively impacted biomass and spectral signature relationships.

Landsat TM data mainly capture the canopy information instead of individual tree information due to its spatial resolution. Other sensor data such as radar data and hyperspectral data can give new insights about biomass estimation. In a large study area such as the Amazon basin, AVHRR or MODIS data, incorporating high spatial resolution data such as Landsat TM images, can be useful in estimating biomass or carbon emission. Some high-resolution data such as IKONOS and Lidar also has the potential to estimate biomass with higher accuracy, providing a means to validate the results derived from TM images.

Many factors can influence vegetation growth vigor, stand structure, and species composition. Such factors can be terrain aspect and slope, soil types, precipitation, road construction, land-use history, population density, etc. Terrain aspect and slope can affect sun illumination and moisture distribution that directly influence plant photosynthesis and biomass accumulation. Different soil types have different physical structures and nutrient components, directly influencing the vegetation growth. Climate conditions, especially precipitation distribution in the Amazon basin, are important factors that affect vegetation vigour. For example, dry weather associated with sandy soil texture structure can wilt the leaves and reduce water content in the leaves quickly, resulting in high biomass consumption and vegetation senescence. Different human activities, such as road construction, selective logging, and mining, land-use history, and population pressures on forest resources also influence the vegetation area loss, disturbance, or fragmentation. The different biophysical conditions affect vegetation growth status and result in different vegetation reflectance captured by remote-sensing sensors. A model that incorporates remotely sensed data and associated ancillary data has the potential to improve model performance and is more applicable to a large study area. Such a model is best developed through integration of geographic information system (GIS) and remote-sensing techniques, and should be especially valuable if the required ancillary data can be captured.

\section{Conclusions}

Multiple regression models that consist of spectral and textural signatures are best for successional and mature forest biomass estimation. They provide better biomass estimation for those forest areas where vegetation is sufficiently dense to cover the ground. Incorporation of texture measures and spectral signatures improved estimation model performance. The models developed cannot, however, 
provide accurate SS1 biomass estimation. The effectiveness of texture measure in models is greatly dependent on the vegetation growth rates and vegetation stand structures. This particular finding that a model comprised of spectral and textural signatures provides better estimation accuracy is valuable in the LBA-Ecology project (Large-Scale Biosphere-Atmosphere Experiment in Amazônia). It is useful for selecting appropriate spectral and textural signatures for developing estimation models in other study areas.

The multiple regression models developed based on integration of Landsat TM images and vegetation inventory data provide a method for biomass estimation using remote-sensing data in areas beyond those defined by sample sites. These models take the advantage of remotely sensed data (digital data format, synoptic view, etc.) to update the biomass distribution image and biomass statistical data in a timely manner. This is especially important in moist tropical areas like the Amazon due to the difficulty in gathering ground-truth data representative of a large area. In a study area with rapid vegetation growth rates, selection of an appropriate texture measure is very important for improving the model performance. In a study area with slow vegetation growth rates, texture measures are relatively less important than spectral signatures. When establishing multiple regression models for biomass estimation, much attention should be paid to the selection of an appropriate texture measure.

Climate conditions, soil types, soil moisture, land-use history, and human activity influence vegetation growth rates, stand structures, species composition, and growth vigour. These factors also influence vegetation reflectance on the TM images. To accurately estimate successional and mature forest above-ground biomass using remotely sensed data, a more advanced model that includes different data sources is important. A combination of GIS data and modelling techniques would likely prove beneficial in this type of research.

\section{Acknowledgements}

The authors wish to gratefully acknowledge support from the National Science Foundation (grants 95-21918 and 93-10049), the National Institutes of Health's NICHD (grant 9710386A), and NASA's LBA program through grant N005-334 that made the data collection and analysis for this paper possible. The authors also wish to acknowledge the assistance of many collaborators in Brazil and at Indiana State University and Indiana University. None of these colleagues or funding agencies should be held responsible for the views presented herein. They are the sole responsibility of the authors.

\section{References}

Anderson GL, Hanson JD (1992) Evaluating handheld radiometer derived vegetation indices for estimating above ground biomass. Geocarto International 7:71-78 
Anderson GL, Hanson JD, Haas RH (1993) Evaluating Landsat Thematic Mapper derived vegetation indices for estimating above-ground biomass on semiarid rangelands. Remote Sensing of Environment 45:165-175

Bannari A, Morin D, Bonn F, Huete AR (1995) A review of vegetation indices. Remote Sensing Reviews 13:95-120

Eastwood JA, Yates MG, Thomson AG, Fuller RM (1997) The reliability of vegetation indices for monitoring saltmarsh vegetation cover. International Journal of Remote Sensing 18:3901-3907

Franklin J, Hiernaux PYH (1991) Estimating foliage and woody biomass in Sahelian and Sudanian woodlands using a remote sensing model. International Journal of Remote Sensing 12:1387-1404

Franklin SE, Peddle DR (1989) Spectral texture for improved class discrimination in complex terrain. International Journal of Remote Sensing 10:1437-1443

Gillespie AJR, Brown S, Lugo AE (1992) Tropical forest biomass estimation from truncated stand tables. Forest Ecology and Management 48:69-87

Gordon DK, Phillipson WR (1986) A texture enhancement procedure for separating orchard from forest in Thematic Mapper imagery. International Journal of Remote Sensing 8:301-304

Haralick RM (1979) Statistical and structural approaches to texture. Proceedings of the IEEE 67(May):786-804

Haralick RM, Shanmugam K, Dinstein I (1973) Textural features for image classification. IEEE Transactions on Systems, Man and Cybernetics SMC-3:610-620

Jakubauskas ME, Price KP (1997) Empirical relationships between structural and spectral factors of Yellowstone lodgepole pine forest. Photogrammetric Engineering and Remote Sensing 63:1375-1381

Leblon B, Granberg H, Ansseau C, Royer A (1993) A semi-empirical model to estimate the biomass production of forest canopies from spectral variables, Part 1: Relationship between spectral variables and light interception efficiency. Remote Sensing Reviews 7:109-125

Lu DS (2001) Estimation of forest stand parameters and application in classification and change detection of forest cover types in the Brazilian Amazon Basin. Ph.D. diss., Indiana State University, Terre Haute, Indiana

Lu DS, Mausel P, Brondizio ES, Moran E ('No Date') Assessment of atmospheric correction methods for Landsat TM data applicable to Amazon basin LBA research. International Journal of Remote Sensing (in press)

Marceau DJ, Howarth PJ, Dubois JM, Gratton DJ (1990) Evaluation of the grey-level cooccurrence matrix method for land-cover classification using SPOT imagery. IEEE Transactions on Geoscience and Remote Sensing 28:513-519

Moran E, Brondizio E, McCracken S ('No Date') Trajectories of land use: soils, succession, and crop choice. In: Wood C et al. (eds) Patterns and Processes of Land Use and Forest Change in the Amazon. Gainesville: University Press of Florida (in press)

Nelson BW, Mesquita R, Pereira JLG, de Souza SGA, Batista GT, Couto, LB (1999) Allometric regression for improved estimate of secondary forest biomass in the central Amazon. Forest Ecology and Management 117:149-167

Nelson R, Krabill W, Tonelli J (1988) Estimating forest biomass and volume using airborne laser data. Remote Sensing of Environment 24:247-267

Nelson RF, Kimes DS, Salas WA, Routhier M (2000) Secondary forest age and tropical forest biomass estimation using Thematic Mapper imagery. Bioscience 50:419-431 
Overman JPM, Witte HJL, Saldarriaga JG (1994) Evaluation of regression models for above-ground biomass determination in Amazon rainforest. Journal of Tropical Ecology 10:207-218

Peddle DR, Franklin SE (1991) Image texture processing and data integration for surface pattern discrimination. Photogrammetric Engineering and Remote Sensing 57:413-420

Roy PS, Ravan SA (1996) Biomass estimation using satellite remote sensing data - an investigation on possible approaches for natural forest. Journal of Bioscience 21:535561

Steininger MK (2000) Satellite estimation of tropical secondary forest above-ground biomass data from Brazil and Bolivia. International Journal of Remote Sensing 21:1139-1157

Tucker JM, Brondizio ES, Moran EF (1998) Rates of forest regrowth in Eastern Amazonia: a comparison of Altamira and Bragantina regions, Para State, Brazil. Interciencia $23: 64-73$ 